\title{
Reestruturação urbana neoliberal e as empresas de ônibus na cidade do Rio de Janeiro
}

Neoliberal urban reorganization and the bus companies in the city of Rio de Janeiro

Igor Pouchain Matela

\begin{abstract}
Resumo
Em 2010, a prefeitura do Rio de Janeiro realizou a concessão privada de todo o sistema de transporte por ônibus na cidade. Historicamente, os empresários do setor se constituíram numa das principais forças na coalizão de interesses na política urbana. Neste artigo, trabalhamos com a hipótese de que a reorganização do transporte está inserida num contexto de aprofundamento do processo de neoliberalização na escala urbana no Brasil que estaria desestruturando/reestruturando a coerência espacial anterior, implicando em mudanças nas coalizões políticas e em suas relações com o Estado. A modernização das formas de acumulação urbana tende a estabelecer uma regulação nos serviços públicos mais próxima da lógica de um mercado autorregulado.
\end{abstract}

Palavras-chave: reestruturação urbana; neoliberalização; transporte público; empresas de ônibus; Rio de Janeiro.

\begin{abstract}
In 2010, the municipal government of Rio de Janeiro granted the private concession of the entire system of bus transportation in the city. Historically, entrepreneurs of the sector have constituted a major force in the coalition of interests in urban policy. In this paper, we work with the hypothesis that the reorganization of the transportation system is embedded in a context of intensification of neoliberalization in the urban scale in Brazil that would be disorganizing /reorganizing the previous spatial coherence, producing changes in political coalitions and in their relations with the State. The modernization of modes of urban accumulation tends to establish a regulation of public services that is close to the logic of a self-regulated market.
\end{abstract}

Keywords: urban reorganization; neoliberalization; public transportation; bus companies; Rio de Janeiro. 


\section{Introdução}

0 transporte na Região Metropolitana do Rio de Janeiro se divide basicamente em cinco modais: ônibus, metrô, trens, barcas e vans (entre legalizadas e clandestinas). Entretanto, destaca-se a primazia do transporte rodoviário por ônibus que pode ser verificada a partir de sua atual participação de cerca de $70 \%$ no total de deslocamentos realizados na cidade do Rio de Janeiro - município núcleo e que apresenta alta concentração dos postos de trabalho e da renda na região metropolitana (Gráfico 1). Os ônibus municipais são os únicos sob administração da prefeitura da cidade, enquanto os outros meios se vinculam ao governo estadual e passaram pelo processo de privatização no fim dos anos 1990.
A hegemonia do modelo rodoviário dominado por empresas de ônibus no sistema de transportes coletivos na cidade do Rio de Ja neiro se consolida a partir da década de 1960 . Desde então, essas empresas reforçaram seu poder econômico e político, tendo grande influência sobre as políticas e os investimentos públicos no setor. Baseadas em permissões da Prefeitura para operar o serviço, as empresas atuavam sob um estatuto jurídico precário, sem contratos definidos. Essa forma de regulação vigorou até 2010, quando a prefeitura da cidade do Rio de Janeiro realizou, pela primeira vez, uma licitação pública para a concessão por 20 anos de todo o sistema de transporte público por ônibus.

Esta mudança se realiza num contexto de grandes transformações urbanas no Rio de Janeiro. A cidade se prepara para receber

\section{Gráfico 1 - Movimento de passageiros segundo os modos de transporte no município do Rio de Janeiro (1995-2012) ${ }^{1}$}

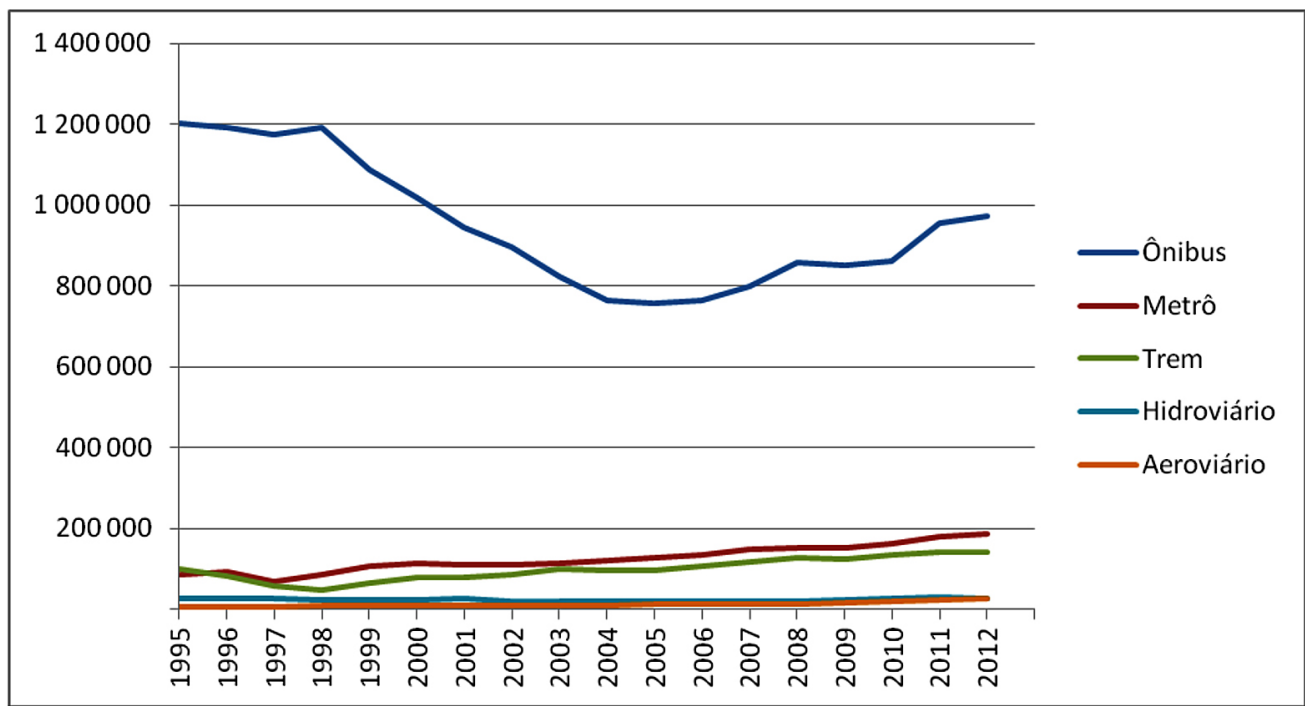

Fonte: Armazém de dados do Rio de Janeiro. 
os dois principais eventos esportivos internacionais (Copa do Mundo e Jogos Olímpicos) e tal situação é vista pela coalizão política dominante como uma oportunidade de inserção competitiva da cidade no mercado mundial. Inclusive, é um momento em que a própria coalizão política parece se rearticular em torno de novos interesses.

As tradicionais coalizões em torno da acumulação urbana no Brasil se organizaram, ao longo da segunda metade do século XX sob a lógica mercantil, a partir de relações patrimonialistas com o Estado. Tal fato conformou um padrão de regulação que bloqueou a modernização capitalista no espaço urbano. As relações de poder garantiram privilégios às frações do capital nacional predominantes nos circuitos de acumulação que envolviam obras públicas, mercado imobiliário e serviços urbanos (especialmente os de transporte). Recorrendo às contribuições de David Harvey, podemos afirmar que essas coalizões foram constitutivas da coerência espacial estruturada característica das cidades brasileiras no período.

Sugerimos que a recente reorganização do transporte por ônibus no Rio de Janeiro aponta para a hipótese de que presenciamos um processo de neoliberalização nos espaços urbanos no Brasil que estaria desestruturando/ reestruturando a coerência espacial anterior, implicando mudanças nas coalizões políticas e suas relações com o Estado.

A partir dessa abordagem, começamos este artigo com uma breve discussão sobre a formação de coerências estruturadas, alianças de classe e coalizões governantes para, em seguida, fazermos uma caracterização da coerência urbana estruturada que se formou no Brasil ao longo do século $X X$, seu padrão de regulação e a coalizão urbana correspondente. Mais especificamente, abordaremos a ascensão das empresas de ônibus e sua consolidação hegemônica no sistema de transporte urbano do Rio de Janeiro.

Na segunda parte, examinaremos a concessão privada do transporte por ônibus realizado a partir de 2010 pela Prefeitura, a racionalidade emergente, o sentido da mudança da regulação e como o processo se desenvolve empiricamente, os conflitos e as adaptações verificados até o momento.

Finalmente, tentaremos oferecer uma interpretação sobre como a reacomodação dos interesses na coalizão urbana implica mudanças/permanências da política de transportes. Em que medida há uma transição da acumulação mercantil, baseada no patrimonialismo para uma lógica de mercado, aprofundando a mercantilização dos serviços urbanos.

\section{Coerência urbana estruturada no período nacional-desenvolvimentista e ascensão das empresas de ônibus no Rio de Janeiro}

\section{Coerências espaciais estruturadas e alianças de classe}

Os processos de circulação do capital, impul sionados pela necessidade sistêmica de incessante acumulação, são o fundamento da geografia histórica do capitalismo. Esta ideia-chave desenvolvida com detalhamento pelo geógrafo David Harvey nos ajuda a interpretar 
as formas mais gerais de produção espacial no capitalismo. Harvey recupera a ideia concebida por Marx de que o movimento de acumulação do capital precisa, a cada rodada, superar as barreiras espaciais a fim de se realizar. Essa tendência de "aniquilação do espaço pelo tempo" se dá pela aceleração do tempo de giro do capital por meio de formas de transporte e comunicações cada vez mais modernas e voltadas para a rapidez dos movimentos. 0 resultado desse processo é a compressão do horizonte espaço-temporal do mundo e tempos de circulação do capital cada vez mais curtos.

Mas desse movimento emerge uma contradição: se por um lado o capital deve superar as barreiras espaciais, por outro ele precisa produzir espaços mais adaptados às suas cambiantes necessidades. Os limites geográficos para acumulação do capital têm de ser ultrapassados pela produção de um novo espaço. Com isso, o capitalismo tende a produzir uma paisagem geográfica apropriada a sua dinâmica de acumulação num determinado momento histórico, para que num momento posterior essa paisagem seja destruída para a criação de uma nova, apropriada à acumulação numa nova condição histórica.

As infraestruturas físicas e sociais são um recurso espacial complexo de ativos criados para apoiar a produção e o consumo. Elas absorvem grandes quantidades de investimento de capital de longo prazo e requerem mais capital para sua manutenção ao longo de sua vida útil. 0 estoque dos ativos de capital incorporado nestas infraestruturas fornece uma forma concreta de riqueza que pode ser usada para produzir e consumir mais riqueza (Harvey, 1985). Dessa forma, as estruturas espaciais consolidadas a partir do processo acima descrito adquirem o caráter de uma configuração espacial particular de um ambiente construído para produção, consumo e intercâmbio. E o acesso privilegiado a qualquer conjunto desses ativos no ambiente construído se constitui numa fonte potencial de lucros extraordinários. Essas configurações espaciais particulares ou, nos termos de Harvey, "coerências estruturadas" dão suporte e, ao mesmo tempo, restringem o movimento do capital.

Dentro desses espaços, a produção, a distribuição, a troca e o consumo, a oferta e a demanda (particularmente de força de trabalho), a luta de classes, a cultura e os estilos de vida se juntam num sistema aberto que, não obstante, exibem algum tipo de "coerência estruturada". (...) Consciências e identidades regionais, até mesmo lealdades afetivas, podem ser construídas nesta região e, quando sobreposta por algum aparato de governança e poder estatal, o espaço regional pode evoluir para uma unidade territorial que opera como um tipo de espaço definido de consumo e produção coletivos assim como de ação política. A coletividade pode se consolidar assumindo responsabilidade pelo enraizamento de todo tipo de infraestruturas na terra (sistemas de rodovias, facilidades portuárias, sistemas de água e esgoto) e configurando múltiplos suportes institucionais (educação e saúde) que definem uma forma particular de relacionamento com a acumulação de capital assim como com o resto do mundo. (Harvey, 2004, p. 78)

Entendemos, portanto, que a formação de coerências estruturadas é um processo que se dá em diferentes escalas simultaneamente e não dependem necessariamente da institucionalização estatal para serem representadas. Assim, se o Estado nacional delimita 
uma coerência estruturada mais geral, outras coerências estruturadas (regionais, metropolitanas, urbanas) podem emergir, estando contidas numa estrutura escalar e estabelecendo diversas formas de relações entre si (competitivas, cooperativas, controle, subordinação hierárquica, etc.).

Se as coerências estruturadas têm essa dimensão sistêmica-estrutural dada pelas condições históricas de acumulação, seu desenvolvimento geográfico desigual também depende da dimensão política específica dada pelas alianças de classe que se formam articuladas a elas. As coerências estruturadas são base material para a formação de alianças de classe e, ao mesmo tempo, destas dependem para sua relativa estabilidade. Há uma lógica política territorial que se apóia em processos vinculados ao espaço. As coerências estruturadas são a materialidade que resulta dessa tensão determinada por forças econômicas e políticas.

0 objetivo mais geral das alianças de classe de base territorial é preservar ou aprimorar a coerência estruturada. Assim, elas podem assumir uma postura defensiva ou agressiva diante de outras regiões, o que interfere sobremaneira no tipo de política territorial a ser adotada. Portanto, a aliança de classe é "uma força poderosa na formação da paisagem do capitalismo, produto da acumulação do capital e luta de classes que se desdobra no espaço geográfico" (Harvey, 1985, p. 148).

As alianças de classe, os processos políticos e as configurações espaciais acabam, em dado momento, por se tornarem barreiras inconciliáveis para o desenvolvimento subsequente do capitalismo. Nesta hora, o capitalismo tem que destruir as formas sócio-políticas-geográficas que ele criou para recriá-las numa versão mais moderna. A reestruturação da coerência espacial cria novas possibilidades para a reconstrução de uma aliança de classes, tanto a partir de ligações externas, quanto por meio de novas combinações das forças internas.

A ideia de configurações geográficas de longa duração, presente no conceito de coerência estruturada, nos permite uma base de análise para as transformações espaciais em curso nas grandes cidades latino-americanas a partir da emergência do processo de neoliberalização. Nos limites deste artigo, pretendemos enfocar em linhas gerais o caso brasileiro para, em seguida, oferecer uma interpretação sobre as mudanças recentes na política de transportes por ônibus na cidade do Rio de Janeiro.

\section{0 período nacional-desenvolvimentista}

A partir de meados do século XX até os anos 1980, se estabelece no Brasil um padrão de regulação da acumulação capitalista que alguns autores classificam como fordismo periférico. Este período, que chamamos aqui de nacional-desenvolvimentista, se caracterizou por uma política industrial com forte incentivo à substituição de importações associada a uma marcante presença de filiais de indústrias de capital estrangeiro no espaço econômico nacional. Como vimos anteriormente, tais características macroestruturais que regularam a acumulação de capital nessa época, ajudaram a conformar, em diferentes escalas, as coerências espaciais e as alianças de classe no Brasil.

Numa abordagem das especificidades do capitalismo associado na América Latina (presença de capitais nacionais e estrangeiros na economia nacional), Lessa e Dain (1982) 
afirmam que uma das condições do desenvolvimento do capitalismo no Brasil nesse período foi o estabelecimento de uma aliança entre os capitais estrangeiros e nacionais que definia duas cláusulas básicas: a primeira consistia em destinar determinadas esferas de acumulação (industrial, bancária, agrária, etc.) para cada tipo de capital. Administrado pelo Estado, o pacto da "Sagrada Aliança" reservou ao capital nacional a acumulação urbana, notadamente os setores imobiliário, de obras e de serviços públicos (ex.: transportes coletivos). A segunda cláusula do pacto garantia ao capital nacional, marcadamente de caráter mercantil, níveis de rentabilidade compatíveis com os auferidos pelo capital industrial estrangeiro. Para isso, eram necessárias formas de acumulação que Lessa e Dain chamaram de "pervertidas", baseadas no privilégio, e que podemos relacionar com as práticas de acumulação por espoliação, de acordo com conceito cunhado por Harvey. Aqui ressaltamos as relações patrimonialistas entre esses capitais mercantis e o Estado, que orientaram de forma decisiva as políticas e os investimentos públicos.

Portanto, é importante notar que a aliança de classes em escala nacional está associada às condições das alianças e coalizões políticas no espaço urbano, assim como as formas de relação entre o Estado e os capitais que aí realizavam sua acumulação. Essas coalizões tiveram notadamente um viés defensivo, de proteção de suas posições alcançadas e de reserva de mercados. Com isso, também foram um fator de bloqueio da modernização capitalista nos espaços urbanos.

Em relação às características distintivas das coerências urbanas estruturadas desse período, podemos destacar a acelerada tendên cia à metropolização e à industrialização com baixos salários. 0 baixo custo de reprodução da força de trabalho teve seus reflexos na economia urbana e na própria produção do espaço: os circuitos inferior e superior da economia (Milton Santos), a informalidade como parte da nossa modernização e não como atraso (Francisco de Oliveira) nos ajudam a compreender as formas de produção, distribuição e consumo nas cidades. Maricato (2000), por exemplo, destaca como nossas cidades se dividem em espaços incorporados ao mercado formal, altamente regulados pelo poder público, enquanto a maior parte se encontra à margem deste mercado e sujeitas à aplicação arbitrária da lei. Além disso, ressalta o caráter altamente regressivo do investimento público, com forte viés de classe e em favor da especulação imobiliária, e o alto grau de segregação socioespacial. Milton Santos ilustra bem a organização interna das cidades resultante destes processos:

Nessas cidades espraiadas (...) há interdependência do que podemos chamar de categorias espaciais relevantes desta época: tamanho urbano, modelo rodoviário, carência de infraestruturas, especulação fundiária e imobiliária, problemas de transporte, extroversão e periferização da população, gerando, graças às dimensões da pobreza e seu componente geográfico, um modelo de centro-periferia. (Santos, 1994, p. 95)

A partir desse contexto analítico, podemos esboçar uma leitura da trajetória de consolidação da hegemonia das empresas de ônibus no setor de transportes urbanos coletivos do Rio de Janeiro. 


\section{Trajetória das empresas de ônibus e a construção de sua hegemonia nos transportes públicos do Rio de Janeiro}

As empresas de ônibus dominam atualmente o setor de transportes coletivos na cidade do Rio de Janeiro. Sua hegemonia no setor e sua importância política na coalizão urbana é resultado de uma trajetória construída ao longo do século XX. As disputas que emergem em torno desse serviço são fundamentais para entender sua ascensão e o controle dos transportes coletivos.

Nos registros históricos, a primeira empresa de ônibus na cidade do Rio de Janeiro surgiu no ano de 1911, dando continuidade a uma linha que, por ocasião das comemorações do centenário da abertura dos portos em 1908, havia sido estabelecida entre a Praça Mauá e o Passeio Público, passando ao longo da Avenida Central (atual Avenida Rio Branco) com eventuais prolongamentos até a Praia VermeIha. Nos anos seguintes, outras empresas surgiram de forma ainda muito incipiente, até que em 1932 é fundada a União das Empresas de Ônibus, primeira organização que vai associar os empresários privados independentes do setor. Até esse momento, os ônibus eram um serviço pouco significativo no conjunto da cidade e, apesar do forte crescimento nesse tipo de transporte na década de 1930, não concorriam diretamente com o transporte ferroviário (bondes e trens), tendo uma função complementar. ${ }^{2}$

A Revolução de 1930 marcou um período de maior atuação do Estado nas políticas públicas no Brasil. Assim, até 1945, foram recorrentes as propostas para monopolização estatal dos transportes coletivos no Rio de Janeiro. Tais propostas não se concretizaram, porém, o maior controle do Estado, restringindo a proliferação de empresas, favoreceu a consolidação daquelas já existentes, marcando o primeiro processo de concentração de capital no setor - o número de empresas se reduz de 24 em 1934 para 16 em 1939. Segundo Freire (2001), na época, o empresariado não tinha força política para estabelecer as diretrizes da política de transportes, por isso a categoria adotava um posicionamento defensivo no sentido de garantir as posições já conquistadas. Os empresários independentes de ônibus eram vistos pelo poder público como desarticuladores do sistema de transportes.

Durante a Segunda Guerra Mundial, as empresas de ônibus são fortemente afetadas pela dificuldade de importação de peças e pelo aumento do custo dos combustíveis. Tais restrições levaram a uma queda generalizada nos padrões de qualidade do serviço (veículos superlotados, mal conservados, etc.). Entretanto, apesar da crise, cresce a participação dos ônibus no transporte urbano, ${ }^{3}$ e o fim do conflito marca uma fase de crescimento e consolidação desse modal na cidade. Veremos como se deu esse processo.

Ao fim da guerra, com a recuperação econômica, o estreitamento das relações políticas e comerciais com os Estados Unidos, 0 reestabelecimento da capacidade de importação e a normalização do abastecimento de combustíveis, houve a criação de condições para que o transporte rodoviário, com motor a explosão, se apresentasse como alternativa de resolução da crise dos transportes urbanos. Novos ônibus estadunidenses de maior capacidade e velocidade passaram a ser importados, favorecidos por financiamentos públicos e pela política cambial. 
Com o fim do Estado Novo, o novo governo assume uma perspectiva mais liberal. As propostas de unificação e coordenação dos transportes coletivos são descartadas e há o incentivo à criação de novas empresas rodoviárias para expandir rapidamente a oferta. Novas linhas são criadas, e o serviço cresce de forma pulverizada e exponencial, principalmente através dos lotações, que passam a competir com os ônibus e bondes. ${ }^{4}$

Os lotações eram veículos menores entre 10 e 21 lugares que haviam surgido durante a guerra e foram tolerados devido à crise nos transportes públicos. Popularizaram-se em função de sua flexibilidade e rapidez e eram operados por motoristas autônomos e sem itinerário fixo até início dos anos 50 . Fizeram forte concorrência tanto com bondes, percorrendo rotas coincidentes, quanto com os ônibus, que tinham menor flexibilidade, pois seus itinerários e frequências eram mais regulados pelo poder público.

Ônibus e lotações atendiam as crescentes periferias urbanas e viabilizavam a expansão da cidade para vastas áreas não servidas por outros meios de transporte. 0 modelo rodoviário, de certa forma, deu condições para uma rápida dinâmica de especulação imobiliária e de periferização da metrópole do Rio de Janeiro. Além disso, favorecia a autoridade municipal ao enfraquecer o poder da Light na política de transportes (Orrico e Santos, 1999).

Portanto, a partir de 1945, há uma nova conformação das forças políticas: enfraquecimento da Light, fortalecimento da posição das empresas de ônibus com legitimação diante do poder público e ascensão dos lotações como concorrentes diretos das empresas estabelecidas. A partir desse momento, o sindicato das empresas de ônibus começa a se colocar também como interlocutor do Estado para a formulação das políticas de transporte, sugerindo medidas e diretrizes. A Light deixa de ser o principal agente dos transportes na cidade e, longe de sua ambição de monopolização dos serviços, começa seu gradual afastamento do setor (Freire, 2001).

0 fim da década de 40 marca o início de uma transição que vai se consolidar nos anos 1960. 0 padrão dominante dos transportes urbanos no Rio de Janeiro deixa de ser ferroviário (bondes e trens) para se apoiar fundamentalmente no modelo rodoviário (ônibus, lotações e automóveis particulares). É um período de muitas intervenções destinadas à circulação rodoviária na cidade (construções de túneis, viadutos, vias expressas). Os ônibus se tornam o principal meio organizador dos transportes, não mais um serviço complementar, enquanto bondes e trens gradualmente se deterioram e perdem sua importância.

A transição rodoviária, até o início dos anos 1960, vai se desenvolver baseada num modelo bastante pulverizado a partir da atuação dos lotações. A multiplicação desse tipo de veículos no transporte urbano criou um ambiente extremamente competitivo e um excesso de veículos disputando passageiros nas ruas. Uma mesma linha era disputada por vários motoristas autônomos. Estima-se que, no fim dos anos 1950, mais de 5.000 lotações circulassem nas ruas da cidade, principalmente entre o centro e a Zona Sul. Havia pouca fiscalização e poucas obrigações por parte dos operadores desse tipo de transporte. Por conta disso, Pereira (1987) afirma que os lotações foram os desestruturadores do antigo modelo. Eles foram responsáveis pelo declínio das 
antigas empresas de ônibus e dos bondes nas principais áreas da cidade e estão na origem da ordem emergente dos transportes urbanos na cidade na década de 60 . A competição imposta por eles, à margem dos regulamentos, fez com que várias das antigas empresas formais de ônibus não resistissem à competição e quebrassem. ${ }^{5}$

Os lotações criaram as condições para 0 surgimento e foram os embriões da segunda geração de empresas de ônibus que veio dominar o transporte público na cidade (Pereira, 1987). De 1958 a 1967, o poder público voltou a atuar de forma mais ativa, e uma série regulações no transporte coletivo por parte da prefeitura deu a base para uma nova conformação do setor e para a definitiva hegemonia das empresas de ônibus no Rio de Janeiro.

Em linhas gerais, a regulação estatal foi no sentido de estimular e, muitas vezes, determinar a concentração do capital no setor, estabelecendo números mínimos para a frota das empresas. Em 1958, é estabelecido o regime de permissões para a exploração do serviço de transporte coletivo. Nesse regime não há prazos definidos de validade nem de reavaliação, não estão claramente estabelecidos quais os direitos e obrigações do permissionário. $\mathrm{Na}$ prática, a permissão veio favorecer as decisões sobre o transporte por parte das empresas de ônibus. Nesse mesmo ano, novas licenças para lotações foram abolidas. Em 1963, os lotações foram definitivamente proibidos, e o ônibus passou a ser o único veículo rodoviário no transporte coletivo. Em 1964, ocorre a extinção dos bondes elétricos e em 67 é estabelecido que as empresas de ônibus deviam ter uma frota mínima de 60 carros para operar, reduzindo de 121 para 54 o número de empresas na cidade. Como resultado, houve uma grande onda de fusões e aquisições, principalmente entre os donos de pequenas frotas de lotações, que se associavam em novas empresas de ônibus para se adequarem à legislação. Portanto, as novas empresas surgiram exatamente dos antigos proprietários dos lotações ou a partir de cooperativas de motoristas. ${ }^{6}$ Além dos empresários que já atuavam no ramo, as novas empresas de ônibus também contaram na origem com o investimento de capitais oriundos de atividades comerciais (mercantis), o que de certa forma ajudou a influenciar o estilo de condução dos negócios, tanto na administração interna quanto nas estratégias de expansão.

A partir dessas medidas emerge a nova lógica dos transportes na cidade: prioridade para os ônibus; regulação estatal no sentido de limitar o número de empresas e restringir a concorrência entre elas; delimitação de área para cada empresa, criando monopólios espaciais; e sistema de permissões (Pereira, 1987).

Autores como Orrico e Santos (1999) e Pereira (1987) apontam a influência dos interesses da indústria rodoviária nessa nova orientação da política de transportes. Fábricas de carrocerias, revendedores de chassis, companhias de petróleo, etc. tinham interesse no desenvolvimento do setor, enquanto a indústria automobilística nascente tinha no mercado das empresas formais de ônibus uma importante demanda, reforçada por regulações que estipulavam prazos de renovação de frota.

Portanto, a década de 60 foi fundamental para a história dos transportes públicos no Rio de Janeiro, pois finalizou o período de transição rodoviária iniciado no pós-guerra e lançou as bases para o domínio e a consolidação do sistema de ônibus no Rio de Janeiro nas décadas 
seguintes. Além disso, Duarte (2003) ressalta que o poder público municipal trouxe para sua esfera administrativa a regulação dos transportes na cidade, uma vez que era mais fácil estabelecer articulações com os novos grupos formados por capitais mercantis locais do que com a Light (empresa canadense que controlava os bondes) ou com o governo federal (responsável pelos trens).

Desde então, a regulação pública induziu cada vez mais a concentração das empresas, incentivando fusões, aquisições, incorporações. Com exigências de frotas mínimas cada vez maiores $(1967=60$ carros; $1981=120$; 1982=240) e critérios bastante restritivos para permissão de linhas, tais políticas funcionaram como impedimento a entradas de novas empresas no sistema. Em 1994, é abolida a exigência de frotas mínimas, mas o controle do setor por parte do sindicato patronal tornou quase impossível novas entradas não consentidas.

Entretanto, o processo de concentração não deve ser analisado apenas pela quantidade de empresas atuantes no setor. A concentração do capital se desenvolveu através de grupos empresariais que controlam mais de uma empresa. A partir de meados dos 90, algumas empresas se dividem, mascarando a concentração empresarial existente. Caiafa ( 2002) argumenta que a cisão de empresas é uma das formas de expansão de capital e incorporação de novos sócios. Ocorre de empresas grandes se fragmentarem em outras menores, com novas diretorias e composição societária diferente. Novos sócios são incorporados, mas mantendo os principais acionistas da empresa anterior. As novas empresas começam a operar sem participar de qualquer licitação, sem a retomada por parte do Estado das linhas que a primeira empresa repassou às outras. A explicação para isso seria que os processos de cisão funcionam como uma forma de revigorar o modelo estabelecido e garantir a continuidade do sistema, promovendo uma repartição do patrimônio e das linhas em muitos casos para acomodar interesses dentro da própria família. ${ }^{7}$

De acordo com estimativas de Orrico e Santos (1999), no ano de 1995, 20 grupos controlavam as 34 empresas existentes na cidade. Destes, dois controlavam $31,1 \%$ e um controlava $24 \%$ da frota total. Em toda RMRJ, $4,1 \%$ dos grupos controlavam $25 \%$ da frota. A distribuição geográfica das concentrações das empresas revelaria situações próximas a monopólios por áreas e trechos. Assim, após um período de incentivo à concentração empresarial por parte do Estado, a partir dos anos 90 a concentração do mercado foi impulsionada a partir dos principais grupos privados do setor.

0 argumento do poder público e dos defensores dos incentivos à concentração de capital era que o grande número de empresas competindo entre si seria um obstáculo ao planejamento e à reorganização do transporte. Porém, o processo de concentração favoreceu a consolidação de poucas e grandes empresas de ônibus privadas que se tornaram cada vez mais poderosas política e economicamente.

Esse poder está vinculado à posição estratégica que as empresas conquistaram na prestação de um serviço essencial para a vida nas cidades, como é o caso dos transportes coletivos. Elas se impuseram e se legitimaram como representantes do setor, influenciando no legislativo e executivo as políticas e os investimentos públicos nas diversas esferas do aparelho de estado. 
Assim, entre a década de 1970 e o ano de 2010, o poder das empresas estabeleceu um modelo que apresentava entre seus principais pontos: controle de um mercado praticamente fechado, com garantia de rentabilidade e bloqueio à entrada de qualquer novo concorrente; monopólios espaciais em determinadas áreas, já que as variações ou mudanças de linhas passaram a ser feitas pelas próprias empresas que nela já operavam, burlando a exigência legal de licitações; faturamento à vista sobre milhões de viagens por dia, grandes ativos imobilizados (garagens, terminais rodoviários, oficinas, etc.); garantia do repasse dos custos para as tarifas por meio de planilhas informadas pelas próprias empresas; consolidação do caráter jurídico de permissionárias.

Na prática, o planejamento do sistema também era feito pelas empresas, mesmo que fragmentariamente, através de solicitações de linhas, acréscimos, desmembramentos. A prefeitura apenas autorizava o que era decidido privadamente. 0 período também foi caracterizado pela resistência a qualquer alteração que não partisse das formulações das próprias empresas.

A organização política da categoria se deu através dos sindicatos patronais. A Fetranspor (Federação das Empresas de Transportes de Passageiros do Estado do Rio de Janeiro) reúne dez sindicatos de empresas de ônibus no estado do Rio de Janeiro e tem um papel de formulação de estratégias e políticas perante as esferas públicas. 0 principal sindicato que compõe a Fetranspor é o Rio Ônibus, que representa as empresas do município do Rio de Janeiro.

Resumindo, Pereira (1987) identifica dois momentos fundamentais na história recente das relações entre o poder público e as empresas de ônibus no Rio de Janeiro. 0 primeiro, ao longo dos anos 1960, de forte intervenção estatal para promover a criação das novas empresas de ônibus (maiores, mais capitalizadas e organizadas) em detrimento dos bondes e lotações. 0 sistema foi organizado através da concessão de privilégios: restrição de permissionárias, reserva de mercado por zonas de operação, estabelecimento de linhas e seções rentáveis em concorrência com outros meios de transporte. 0 poder público organizou o sistema de transportes e concedeu um mercado cativo, de alta liquidez às empresas de ônibus, que passaram a atuar no sentido de manter essa situação. No segundo momento, o sistema se consolida em grupos crescentemente mais concentrados e poderosos, com um sindicato forte e hegemonia no transporte municipal e metropolitano. As políticas do setor passam cada vez mais pelo aval das empresas (na verdade, muitas vezes as políticas são formuladas a partir das empresas). Mais uma vez a preocupação central do setor foi preservar a posição estratégica conquistada, com duas linhas de atuação: 1) ampliar as articulações/relações dentro do Estado (legislativo, executivo e judiciário); 2) aumentar a eficiência e produtividade em nível microeconômico (com a contratação de consultores, profissionalização).

Entendemos que, a partir de 2010, com a concessão abrangente do sistema de transporte por ônibus no município do Rio de Janeiro, se estabelece um terceiro momento nessa relação entre as empresas e o poder público. É essa questão que procuraremos analisar a seguir. 


\section{Reestruturação urbana neoliberal e rearticulações das coalizões políticas}

\section{Transição neoliberal}

A partir dos anos 1990, inicia-se um processo de transformações no capitalismo brasileiro fundado na liberalização da economia. Desde então, esse processo se aprofunda, interpenetra as escalas territoriais e alcança com força a produção do espaço urbano a partir da segunda metade da década de 2000. Evidenciam-se com mais clareza os processos de financeirização e globalização da urbanização, com destaque para o circuito imobiliário (Harvey, 2012). Nesse mesmo contexto, a chegada de novos agentes e novos circuitos na acumulação urbana estaria pressionando a transformação da cidade (coerências urbanas estruturadas) e a redefinição da coalizão de interesses em torno da acumulação urbana em bases distintas do patrimonialismo historicamente estabelecido.

Cabe pontuar que entendemos neoliberalização como um processo de aprofundamento da mercantilização e da adoção da lógica de mercado aplicada à regulação estatal dos serviços públicos, nos termos apresentados em diversos trabalhos por Jamie Peck, Neil Brenner e Nik Theodore. A partir dessa abordagem, a neoliberalização não é uma coisa ou uma situação ideal, mas um processo dependente da trajetória e que se dá de forma variada (variegated) de acordo com as paisagens regulatórias herdadas, gerando formas contextualmente específicas. Da incidência da neoliberalização nos espaços concretos singulares resulta uma redefinição das arenas e dos interesses políticos em que se articularão as disputas em torno da acumulação. Nessa perspectiva,

[...] a neoliberalização deveria ser concebida como um ethos hegemônico de reestruturação, um padrão dominante de transformação regulatória (incompleta e contraditória), e não como um sistema plenamente coerente ou uma forma de Estado tipológica. Como tal opera entre seus 'outros' em ambientes de governança múltipla, heterogênea e contraditória. (Peck, Theodore e Brenner, 2012, p. 69)

Dessa forma, mesmo que apresente características gerais semelhantes (como sistemas de governança e de regulação pró-mercado), a neoliberalização é sempre contextualizada e convive de forma "parasitária" em combinações híbridas com as formações sociais locais - diferentes tipos de Estados de Bem Estar Social, o socialismo chinês, governos com viés de esquerda na América do Sul e, no caso brasileiro, com o 'lulismo'. É no antagonismo às formações sociais locais e na resistência social que são forjados os desenvolvimentos geográficos desiguais da neoliberalização de acordo com os contextos. Isso implica um grau de variação bastante complexo, que não pode ser simplesmente resumido entre neoliberalismo e não neoliberalismo.

Portanto, o processo de neoliberalização e reestruturação urbana em curso no Rio de Janeiro possibilita fraturas nas antigas coalizões urbanas fundadas na acumulação mercantil e abre oportunidades para novos agentes entrarem no jogo e redefinirem as relações de poder. Nesse contexto, emergem formas de gestão urbana 'empresarialistas', ligadas aos circuitos internacionais de acumulação e aos agentes econômicos e políticos organizados 
em torno da transformação das cidades em projetos especulativos:

Pode-se observar nas cidades brasileiras, com efeito, a emergência de uma governança empreendedorista empresarial que mantém as antigas práticas patrimonialistas de acumulação urbana e de representação baseadas no clientelismo, e às vezes incorpora parte do discurso universalista em torno da cidadania, ao mesmo tempo em que promove novas práticas orientadas pela transformação das cidades em commodities.(...) Em síntese, estar-se-ia diante da emergência de uma nova coalização de forças sociais nas metrópoles, expressando um bloco de interesses em torno de uma governança empreendedorista empresarial, em aliança com antigas coalizões dominantes (caracterizadas pelo localismo, paroquialismo e clientelismo), envolvendo também, de forma minoritária, setores dos segmentos populares e progressistas. Essa nova coalizão de forças seria sustentada por frações do capital imobiliário em aliança com frações do capital financeiro, líderes partidários e parte da tecno-burocracia do estado, e estaria fortemente vinculada a algumas formas de intervenção urbana, em especial, vinculadas à reestruturação das áreas centrais, à promoção dos mega-eventos, às grandes obras infraestruturais (como as obras viárias e de saneamento básico), à urbanização e ordenação das favelas, e à infraestrutura vinculada ao turismo imobiliário. (Ribeiro e Santos Junior, 2013, p. 36)

É um processo não linear de modernização capitalista das cidades brasileiras que leva a mudanças nos modos de acumulação urbana com todo um conjunto de efeitos nas formas de produção do espaço. Obviamente, o resultado final desse processo não está dado, depende de disputas políticas, econômicas, sociais e espaciais. Os agentes tradicionais procuram manter suas posições de privilégio e precisam adaptar seus modos de exercer o poder. Portanto, devemos observar empiricamente em que medida esse processo se desenvolve e como os diversos agentes produtores do espaço se posicionam.

\section{A reorganização do sistema de ônibus no Rio de Janeiro}

Em abril de 2010, a prefeitura do Rio de Janeiro anunciou a intenção de realizar uma licitação geral das linhas de ônibus da cidade. De acordo com a explicação oficial, a medida se justificava porque:

No Rio de Janeiro, o modelo vigente há décadas, de permissões para as empresas operarem linhas de ônibus, tem prejudicado a organização e a racionalização do sistema e estimulado a concorrência predatória entre os diversos modos de transporte que operam na cidade, em detrimento da integração. (Rio de Janeiro, 2010, p. 62)

Assim, em junho, a Secretaria Municipal de Transportes (SMTR) lançava o edital do processo que pretendia reorganizar o transporte por ônibus na cidade, normatizar o serviço e racionalizar as linhas. 0 anúncio prometia uma transformação radical na circulação das pessoas na cidade, pois, pela primeira vez, a Prefeitura do Rio de Janeiro realizava uma licitação pública, aberta à concorrência internacional, para a concessão privada de todo o sistema de transporte por ônibus. Uma mudança fundamental era a que alterava a relação do poder concedente (prefeitura) com as empresas 
de ônibus, que deixaram de ser permissionárias para se tornarem concessionárias. Até então, com o modelo de permissões, cada empresa projetava as linhas de acordo com seus interesses particulares e apresentava a proposta à SMTR, que decidia pela autorização de operação. No modelo de concessão, o poder público disporia de mais instrumentos de regulação, havendo um contrato formal e um planejamento abrangente do sistema de transporte.

0 discurso da Prefeitura centrava-se na argumentação de que o sistema precisava ser racionalizado para que todos na cidade ganhassem com a melhora de eficiência. Ou seja, a adequação da oferta de ônibus à demanda de passageiros, abolindo a concorrência nas ruas, diminuiria o custo das empresas e consequentemente o valor da tarifa. Em linhas gerais, pode-se dizer que a racionalização significava reduzir o número de ônibus nas zonas Sul, Norte, Barra da Tijuca e Jacarepaguá, onde havia excesso de veículos e grande disputa de mercado com linhas sobrepostas, e aumentar na Zona Oeste, área de escassez na oferta de transporte.

A concessão dividiu a cidade em cinco regiões, chamadas de Redes de Transportes Regionais (RTRs): RTR 1 (Centro e zona portuária), que por ser destino de várias linhas e de uso comum, não entrou na licitação; RTR 2 (Zona Sul e Grande Tijuca); RTR 3 (83 bairros da Zona Norte); RTR 4 (Baixada de Jacarepaguá, Barra da Tijuca e Recreio); e RTR 5 (Zona Oeste). As linhas que integrassem mais de uma região estariam vinculadas à RTR com maior número de embarques de passageiros. É importante destacar que cada consórcio deveria controlar uma RTR. Reforçando a concepção de pôr fim à competição territorial entre as empresas de ônibus, garantindo uma área delimitada - e exclusiva - para a atuação de cada consórcio vencedor da licitação.

Ao fim do processo de licitação, os quatro consórcios que representavam 40 das 47 empresas de ônibus que já operavam no Rio de Janeiro foram anunciados como habilitados para a concessão do serviço por 20 anos. De acordo com estimativas do edital, durante esse período de concessão, as passagens pagas pelos usuários somariam $\mathrm{R} \$ 15,9$ bilhões, enquanto os concessionários deveriam investir $\mathrm{R} \$ 1,8$ bilhão no serviço. Além disso, a prefeitura conseguiu aprovar na Câmara de Vereadores projeto de lei no qual do ISS (Imposto Sobre Serviços de Qualquer Natureza) do setor de transportes foi reduzido de $2 \%$ para $0,01 \%$ da arrecadação, o que significava, em valores da época, uma renúncia fiscal de $R \$ 33 \mathrm{mi}$ Ihões por ano.

Ficou estabelecido também que os consórcios vencedores da licitação viriam operar os futuros corredores expressos de ônibus (Bus Rapid Transit - BRT) entre Barra da Tijuca e o Aeroporto Internacional do Galeão (Transcarioca); entre Barra da Tijuca e Santa Cruz (TransOeste); entre Recreio dos Bandeirantes e Deodoro (TransOlímpica) e entre Deodoro e o Aeroporto Santos Dumont (TransBrasil).

A concessão abrangente do sistema de transporte por ônibus, com a relação entre a Prefeitura e as empresas de ônibus regidas por um contrato público e com prazo determinado, poderia, a princípio, ser apontada como uma ruptura com o modelo de regulação anterior. Entretanto, o desenvolvimento do processo na prática envolve uma série de contradições e complexidades que devem ser observadas para uma interpretação mais precisa da questão. 
Após três anos de concessão, a estrutura montada através dos consórcios operadores e em torno deles indica a manutenção reformulada das tradicionais práticas utilizadas pelas empresas e de suas relações com o Estado. Além disso, percebe-se uma tendência de reforço da concentração de capital, poder e informação. 0 desenrolar do processo após a concessão indica a tendência de modernização do negócio por parte dos grupos empresariais dominantes como uma estratégia de reposicionamento na coalizão política que se atualiza. Tentaremos a seguir embasar essa afirmação.

Como ressaltado anteriormente, a organização empresarial no setor apresenta peculiaridades que complexificam a análise: se no início da concessão 40 empresas formavam os consórcios, hoje são 42. Dessas, 15 participam de dois consórcios diferentes e duas delas participam de três consórcios. ${ }^{8} \mathrm{~A}$ maior parte dos empresários tem participação acionária distribuída em duas ou mais empresas e apenas sete delas apresentam sócios exclusivos. A concentração por grupos indica que os três principais detêm metade da participação acionária do conjunto dos consórcios, reafirmando o poder que esses grupos tinham desde antes da concessão. Os indícios de irregularidades na licitação e suspeita de acordo prévio entre as empresas de ônibus que já atuavam na cidade para definir os vencedores da licitação fizeram com que o Tribunal de Contas do Município (TCM) iniciasse uma ampla apuração do processo.

A família Barata, por exemplo, líder do principal grupo controlador de empresas de ônibus no Rio de Janeiro, também atua no financiamento da compra de veículos para a maior parte das empresas e para o sistema
BRT através de seu braço financeiro, o Banco Guanabara. Os ônibus são comprados na concessionária Guanabara Diesel, também do grupo que, dessa forma, tornou-se credor de várias empresas menores. 0 controle das frotas de ônibus dos consórcios por GPS também é realizado por uma empresa da família.

Entretanto, a compreensão dos mecanismos de controle e concentração de poder privado no setor passa pela Fetranspor. A partir de 2010, a federação dos sindicatos criou uma série de empresas para atuar em negócios relacionados ao transporte. Entre elas encontram-se agências de publicidade para ônibus (MOVTV); uma administradora para os terminais rodoviários urbanos (RioTer); participação acionária no transporte por barca (SPTA) e no futuro veículo leve sobre trilhos a ser instalado na área central da cidade (RioPar Participações). Mas a empresa-chave criada pela Fetranspor é a RioCard Cartões. Ela foi criada para instalar e operar o sistema de cobrança de passagem por meio de cartão eletrônico (Bilhete Único). 0 controle da Fetranspor foi garantido pelo Estado, ao estabelecer que a administração desse sistema deveria ser realizada pelas empresas de ônibus ou entidade por elas escolhida.

Através da implementação da bilhetagem eletrônica (2005), a receita das empresas de ônibus passou a ser centralizada na RioCard (não somente a receita das tarifas, mas também receitas obtidas de subsídios da prefeitura para transporte escolar, vale-transporte, etc.). Assim, o grupo de empresários que comanda a Fetranspor gerencia as receitas e tem acesso exclusivo a toda contabilidade do sistema. As vans legalizadas também pagam uma taxa de administração para a RioCard. 
Ocorre que, com o controle centralizado da informação, a divisão das receitas arrecadadas no sistema de ônibus e a prestação de contas são feitas a partir da Fetranspor. Portanto, grupos minoritários de empresários de ônibus acabam não tendo acesso completo aos critérios de rateio das verbas oriundas de tarifas e outras fontes. Tais grupos perdem poder sobre seus próprios capitais e as informações do sistema. Também para o poder público, o controle se torna precário. Relatório do TCM avaliou que a prestação de contas dos consórcios não é confiável, e a Prefeitura não tem informações exatas sobre a rentabilidade do setor. 0 próprio estudo de cálculo para reajuste tarifário não é feito pela Prefeitura, mas por consultoria contratada pela Fetranspor e a partir de dados por ela fornecidos. Com imensas dificuldades de controle, 0 poder público - TCM, vereadores e a própria Prefeitura - dificilmente tem acesso às informações completas do setor.

Na prática, a Fetranspor realiza a gestão privada de todo o negócio que envolve o transporte público por ônibus no Rio de Janeiro, um setor fundamental para a vida na cidade e com uma capacidade enorme de acumulação de capital (faturamento anual bruto estimado em 2,6 bilhões de reais). A famosa "caixa-preta" das empresas de ônibus consiste na restrição ao acesso das informações do setor. A Fetranspor, por sua vez, é controlada por um pequeno grupo de empresários dominantes que comandam um complexo esquema de privatização das atividades de controle e operação do sistema de ônibus.

Outra situação obscura ocorreu em 2012, quando, sem concorrência pública e a partir de um acordo entre as empresas, foi criado um "consórcio operacional" com a finalidade de operar os BRTs. Esse seria uma espécie de "consórcio terceirizado", contratado pelos consórcios oficiais exclusivamente para gerir o transporte nos BRTs. A "terceirização" do serviço funcionou como forma de permitir que a escolha das empresas que participam do novo consórcio se desse internamente, sem interferência do poder público. Não por acaso, as empresas operadoras do BRT não pertencem aos grupos dominantes. De acordo com estimativas da Prefeitura, quando estiverem em pleno funcionamento, $50 \%$ das viagens por ônibus serão realizadas nos corredores BRT, o que dá a dimensão de um negócio extremamente promissor para as poucas empresas escolhidas que irão administrá-lo.

\section{Considerações finais}

Interpretamos que o processo de neoliberalização, ao atingir as cidades brasileiras (e o exemplo mais explícito é o da cidade do Rio de Janeiro), desestrutura e reestr tura as coerências espaciais herdadas do momento histórico anterior, além de reconstruir em novas bases as alianças de classe e coalizões de poder.

As antigas alianças de classe fundadas na acumulação mercantil precisam se modernizar e/ou elaborar novas estratégias políticas para se articular às formas financeirizadas de acumulação. Essas novas coalizões tendem a substituir antigas estratégias defensivas de reprodução de poder por estratégias competitivas de empreendedorismo urbano, e utilizar a cidade como "máquina de crescimento" 
(Molotch, 1976). Esse movimento de inserção competitiva das cidades está em sintonia com o processo de globalização e financeirização da urbanização (Harvey, 2012), impulsionado pela atual crise no capitalismo central que forçou os excedentes de capital a buscarem novos espaços de reprodução. Fica claro que o entendimento do processo em questão atravessa várias escalas geográficas.

Em relação ao objeto do presente artigo, procuramos pensar as mudanças do modelo historicamente privado de ônibus no contexto da neoliberalização. Várias formas de capital coexistem no mesmo espaço e se apoiam mutuamente. 0 velho capital mercantil das empresas de ônibus se articula com as novas formas de acumulação urbana dos capitais nacionais e transnacionais.

A circulação de pessoas é um aspecto fundamental na cidade e por isso não pode ser negligenciada pelos esquemas de dominação econômica e política. A legitimação da coalizão urbana e suas condições de acumulação passam por uma organização dos transportes mais eficiente. Portanto, interpretamos as mudanças observadas no setor como necessárias para sustentar a modernização urbana por meio de uma reestruturação neoliberal.
Mas se falamos em mudanças, entendemos que em linhas gerais elas se configuram mais como tendências que rupturas. As antigas coalizões não se desfazem, mas se repactuam.

A concessão de 2010 marca um momento de aprofundamento da lógica de mercado na regulação e operação dos transportes por ônibus e todas as atividades que dão suporte a seu funcionamento modernizado. A concentração empresarial e controle do setor passam por grupos que, ao controlarem crescentemente o fluxo de capital e informações, tendem a acumular mais poder. 0 Estado parece perder influência e capacidade nas decisões, emergindo uma forma de regulação que deixa gradativamente de se basear no patrimonialismo historicamente constituído para aproximar-se de um modelo mais voltado para uma autorregulação de mercado. Interpretamos que esse processo está inserido especificamente no contexto da neoliberalização da coerência urbana estruturada no Rio de Janeiro, mas também articulado com transformações gerais das relações capital/Estado em escala nacional. Por outro lado, e não sendo contraditório, as antigas práticas de acumulação por espoliação, os privilégios de uma regulação baseada no patrimonialismo, não desaparecem, mas se adaptam.

\section{Igor Pouchain Matela}

Geógrafo. Rio de Janeiro/RJ, Brasil.

igormatela@hotmail.com 


\section{Notas}

(1) Não computados neste gráfico os dados relativos à participação das vans legais e clandestinas. Porém, infere-se que a curva descendente a partir do final dos anos 1990 esteja relacionada à concorrência desse tipo de transporte, o que levou as empresas de ônibus a pressionarem a Prefeitura por ações de repressão e controle.

(2) De acordo com Barat (1975), em 1940 o transporte ferroviário (trens e bondes elétricos) tinha uma participação de $83,47 \%$ dos passageiros na cidade.

(3) Freire (2001) aponta que entre 1934 e 1944 o aumento do volume de passageiros transportados ultrapassa os $100 \%$ (de 48 para 100 milhões).

(4) Como exemplo, Freire (2001) aponta que entre 1946-1948 surgem seis novas empresas de ônibus e a frota total passa de 812 para 1.024 carros.

(5) Somente quatro empresas de ônibus sobreviveram ao período de concorrência aberta com os lotações.

(6) É importante perceber que a origem da formação dessas empresas tem reflexos na composição que elas assumem até os dias atuais: como observa Caiafa (2002), a história das empresas se desenvolveu muitas vezes de acordo com as histórias pessoais de seus donos. As empresas surgem com alguns sócios, que depois se separam, outras vezes se fundem, cedem ou recebem determinadas linhas a outrem, negociam veículos, repassam cotas a herdeiros, etc.

(7) O monopólio dos ônibus na cidade do Rio de Janeiro é controlado por um pequeno número de empresários familiares. São grupos familiares que têm grande poder de barganha na política local.

(8) http://www.rioonibus.com/rio-onibus/consorcios-e-empresas/

\section{Referências}

BARAT, J. (1975). Estrutura metropolitana e sistema de transportes: estudo do caso do Rio de Janeiro. Rio de Janeiro, Instituto de Planejamento Econômico e Social/INPES.

BRENNER, N.; PECK, J. e THEODORE, N. (2012). Após a neoliberalização. Cadernos Metrópole. São Paulo, v. 14, n. 27, pp. 15-39.

CAIAFA, J. (2002). Jornadas urbanas: exclusão, trabalho e subjetividade nas viagens de ônibus na cidade do Rio de Janeiro. Rio de Janeiro, FGV.

DUARTE, R. (2003). Centralidade, acessibilidade e o processo de reconfiguração do sistema de transporte na metrópole carioca dos anos de 1960. Revista Território. Rio de Janeiro, ano VII, n. 11-12-13. 
FREIRE, A. (2001). Guerra de posições na metrópole: a prefeitura e as empresas de ônibus no Rio de Janeiro (1906-1948). Rio de Janeiro, ALERJ/FGV.

HARVEY, D. (1985). "The place of urban politics in the geography of uneven capitalist development". In: HARVEY, D. The Urbanization of Capital. Baltimore, The Johns Hopkins University Press.

(2004). "Notes towards a theory of uneven geographical development". In: Spaces of neoliberalization. Stuttgart, Hettner-Lectures v. 8, Steiner Verlag.

(2005). "A geografia da acumulação capitalista: uma reconstrução da teoria marxista". In: HARVEY, D. A produção capitalista do espaço. São Paulo, Annablume.

(2012). Rebel Cities. Londres, Verso.

LESSA, C. e DAIN, S. (1982). "Capitalismo associado: algumas referências para o tema estado e desenvolvimento". In: COUTINHO, R. e BELLUZZO, L. G. M. (orgs.). Desenvolvimento capitalista no Brasil: ensaios sobre a crise. São Paulo, Brasiliense.

MARICATO, E. (2000). "As ideias fora do lugar e o lugar fora das ideias”. In: ARANTES, O. et al. A cidade do pensamento único. Petrópolis, Vozes.

MOLOTCH, H. (1976). The city as a growth machine: toward a political economy of place. American Journal of Sociology, v. 82, n. 2, pp. 309-332.

ORRICO, R. e SANTOS, E. (1999). "Hegemonia privada: da capital do bonde ao ônibus no Rio de Janeiro”. In: BRASILEIRO A. e HENRY, E. (orgs.). Viação ilimitada: ônibus das cidades brasileiras. São Paulo, Cultura Ed. Associados.

PECK, J.; THEODORE, N. e BRENNER, N. (2012). Mal-estar no pós-neoliberalismo. Novos Estudos Cebrap. São Paulo, n. 92, pp. 59-78.

PEREIRA, V. (1987). Avaliação da política de transportes públicos no Rio de Janeiro: causas e consequências do modelo privado no transporte por ônibus. Brasília, EBTU.

RIBEIRO L. C. Q. e SANTOS JUNIOR, O. A. (2013). Governança empreendedorista e megaeventos esportivos: reflexões em torno da experiência brasileira. O Social em Questão. Rio de Janeiro, ano 16, n. 29 , pp. 23-42.

RIO DE JANEIRO (2010). Ato de justificação da outorga de concessão da prestação de serviço público de transporte coletivo de passageiros por ônibus. Diário Oficial do Município do Rio de Janeiro. Rio de Janeiro, ano XXIV, n. 29, p. 62, 29 abr.

SANTOS, M. (1994). A Urbanização Brasileira. São Paulo, Hucitec.

THEODORE, N.; PECK, J. e BRENNER, N. (2009). Urbanismo neoliberal: la ciudad y el imperio de los mercados. Temas Sociales. Santiago de Chile, v. 66, pp. 1-12.

Texto recebido em 1/set/2013 Texto aprovado em 26/out/2013 
